\title{
"Clicked" Porphyrin-Cucurbituril Conjugate: A New Multifunctional Supramolecular Assembly Based on Triglycosylated Porphyrin and Monopropargyloxycucurbit[7]uril
}

\author{
Ahmet Koc, ${ }^{[a]}$ Rehan Khan, ${ }^{[a, b]}$ and Dönüs Tuncel ${ }^{*[a, b]}$
}

Abstract: The design, synthesis, and characterization of a new multifunctional supramolecular assembly based on a photoactive glycosylated porphyrin and covalently attached monofunctionalized cucurbit[7]uril (CB7) are reported. To obtain the target supramolecular assembly, azido-functionalized tetraphenylporphyrin (TPP) was used as a building block. TPP was first glycosylated by copper-catalyzed azidealkyne cycloaddition (CUAAC) reaction, then a monopropargyloxy-functionalized-CB7 unit was conjugated to glycosylat- ed TPP with a second CUAAC reaction. The host-guest chemistry of the assembly was investigated by ${ }^{1} \mathrm{H}$ NMR experiments to establish the availability of the CB7 as a host. The imidazole-based guest, which is known to have high affinity toward CB7, was observed to form inclusion complex with CB7. It was also demonstrated that this supramolecular assembly can serve as an efficient photosensitizer for the generation of singlet oxygen.

\section{Introduction}

Multifunctional supramolecular materials combining various important functions and abilities in one platform can find a wide range of applications in the emerging technologies. ${ }^{[1]}$ In this regard, porphyrin derivatives are highly appealing as a chromophore and a building block in the construction of photoactive multifunctional assemblies because they can exhibit photocatalytic, photodynamic and electroactive properties and allow the attachment of various functionalities to their large hydrophobic cores, thereby bringing together multiple functionalities. ${ }^{[2-7]}$

A number of different functional groups were attached to the porphyrin core, including hydrophilic oligoethylene glycols, dendrons, and mono- or polysaccharides to alter the solubility and photophysical properties and to make use of these compounds for various applications (e.g., photocatalysis, light harvesting, sensing, photodynamic therapies, etc.). ${ }^{[8-14]}$

There are also examples in which cucurbit $[n]$ urils (CBs) are attached to the porphyrin core through noncovalent interactions ${ }^{[15,16]}$ however, those studies do not involve the conjugation of functionalized CBs directly to the porphyrin core and

[a] A. Koc, Dr. R. Khan, Prof. D. Tuncel Department of Chemistry, Bilkent University, 06800 Ankara (Turkey)

[b] Dr. R. Khan, Prof. D. Tuncel

UNAM-National Nanotechnology Research Center

Institute of Materials Science and Nanotechnology Bilkent University, Ankara 06800 (Turkey)

E-mail:dtuncel@fen.bilkent.edu.tr

$\square$ Supporting information and the ORCID identification number(s) for the au-

(iD) tho thor(s) of this article can be found under:

https://doi.org/10.1002/chem.201804024. It contains the experimental details and procedures, characterization data, and spectra. enabling the CBs to be utilized as receptors. CBs are highly versatile macrocycles possessing a hydrophobic cavity along with carbonyl decorated hydrophilic portals. Given these features, they have an ability to bind to various guests, including dyes, drugs, and peptides, with high affinity and selectivity. Their distinctive features mean that they have been utilized in the construction of supramolecular assemblies. ${ }^{[17]}$ Although post-surface functionalized CBs with reactive functional groups are very useful building blocks for the assembly of supramolecular structures, the examples are still rather limited. One of the reasons might be the difficulties associated with the functionalization of CB derivatives, especially monofunctionalization. ${ }^{[18-23]}$ To date, mainly two approaches have been employed for the synthesis of functionalized $C B$ derivatives: 1) post-functionalization ${ }^{[19-22]}$ and 2) the use of functionalized precursors. ${ }^{[23,24]}$ Postfunctionalization seems to be more practical because it allows the modification of as-prepared CB homologues in moderate yields. Kim et al. used these functionalized $C B$ derivatives in the preparation of various nanostructured materials. ${ }^{[20,17 \mathrm{~b}, \mathrm{~d}]}$ Isaacs and co-workers recently reported the synthesis and the application of monofunctionalized CB7 derivatives, which was synthesized from a functional-group-containing precursor. $^{[23,24]}$

Here, we report first time the conjugation of a monopropargyloxy-CB7 unit to a trimannosylated-TPP core has been achieved through copper-catalyzed azide-alkyne cycloaddition (CUAAC) reaction. The rationale behind the design of this assembly was as follows: TPP was selected as a core of the assembly because of its singlet oxygen $\left({ }^{1} \mathrm{O}_{2}\right)$ production ability, which could be used as a photosensitizer for photodynamic therapies against cancer cells or bacteria inactivation as well as in photocatalysis. Multiple mannose groups were chosen 1) because of their hydrophilic nature, which may increase the solubility of the resulting assembly and 2) because they enable 
multivalent interaction; the mannose units can interact with mannose receptors on the bacterial surface, which would be useful for photodynamic antibacterial therapy. CB7 was chosen to be conjugated to this platform for several reasons. First, because of its bulky nature, interactions between the porphyrin units are expected to be minimized and, as a result, singlet oxygen production efficiency will be enhanced. To increase the efficiency of photodynamic cancer or antibacterial therapies, anticancer drugs or antibiotics, respectively, can be further encapsulated and carried by CB7 units. This assembly could also be used for photocatalysis and energy harvesting in which $C B$ units could encapsulate, respectively, an analyte and donor/acceptor molecules for efficient photocatalytic and energy transfer processes. However, in this manuscript will focus on the synthesis, full characterization, host-guest chemistry and singlet oxygen generation ability of the assembly. Other aforementioned applications will be explored in our future works.

\section{Results and Discussion}

The synthetic route to our target assembly is shown in Scheme 1. First, CB7 was synthesized and characterized by ${ }^{1} \mathrm{HNMR},{ }^{13} \mathrm{C}$ NMR spectroscopic and ESI-MS analyses (Figures $\mathrm{S} 1-\mathrm{S} 4)^{[25]}$ Then, monohydroxy-CB7 $\left(\mathrm{CB}^{2}-\mathrm{OH}_{1}\right)$ and mono- propargyloxy-cucurbit[7]uril (CB7-(O-propargyl) $)_{1}$ ) were prepared as shown in Scheme $1 \mathrm{a}$ according to reported procedures. $^{[19-21]}$ The formation of $\mathrm{CB}^{-\mathrm{OH}_{1}}$ and CB7-(O-propargyl) was confirmed by ${ }^{1} \mathrm{H}$ NMR, ${ }^{13} \mathrm{C}$ NMR spectroscopic, ESI-MS, and FTIR analyses, and thermal characterization was based on TGA (Figures S5-S13).

With monopropargyloxylated CB7 in hand, we embarked on the synthesis of the porphyrin derivatives. First, the synthesis of 5,10,15,20-tetrakis( $\alpha$-bromo- $p$-tolyl)porphyrin (TPP-Br) was accomplished $^{[26]}$ followed by azidation to afford TPP- $\mathrm{N}_{3}$ in $93 \%$ yield. TPP-Br and TPP- $\mathrm{N}_{3}$ were characterized by ${ }^{1} \mathrm{H}$ NMR spectroscopy and ESI-MS analyses (Figures S14-S18). Before proceeding with Cu-catalyzed azide-alkyne click reaction (CuAAC), the core of TPP- $\mathrm{N}_{3}$ was metalated with $\mathrm{Zn}$ so as to prevent inclusion of $\mathrm{Cu}$, which will decrease its catalytic effect. Metalation was successfully achieved by refluxing TPP- $\mathrm{N}_{3}$ with $\mathrm{Zn}(\mathrm{OAc})_{2}$ in $\mathrm{MeOH}$ and characterized by ${ }^{1} \mathrm{H}$ and ${ }^{13} \mathrm{C}$ NMR spectroscopy, ESI-MS, FTIR and TGA (Figures S19-S23). In the ${ }^{1} \mathrm{H}$ NMR spectrum, the upfield shift from $4.88 \mathrm{ppm}$ to $4.75 \mathrm{ppm}$ and the disappearance of the singlet at $-2.78 \mathrm{ppm}$ constituted proof of the successful metalation. TGA of the compound demonstrated two types of decomposition (Figure S23). The first decomposition started at $233^{\circ} \mathrm{C}$, which is due to the loss of azide groups from the compound. The second decomposi-

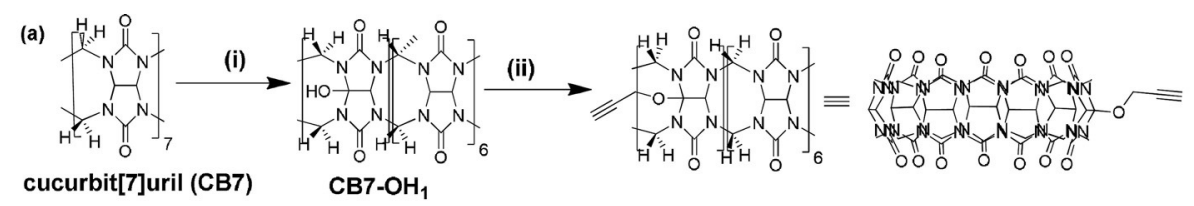

(b)

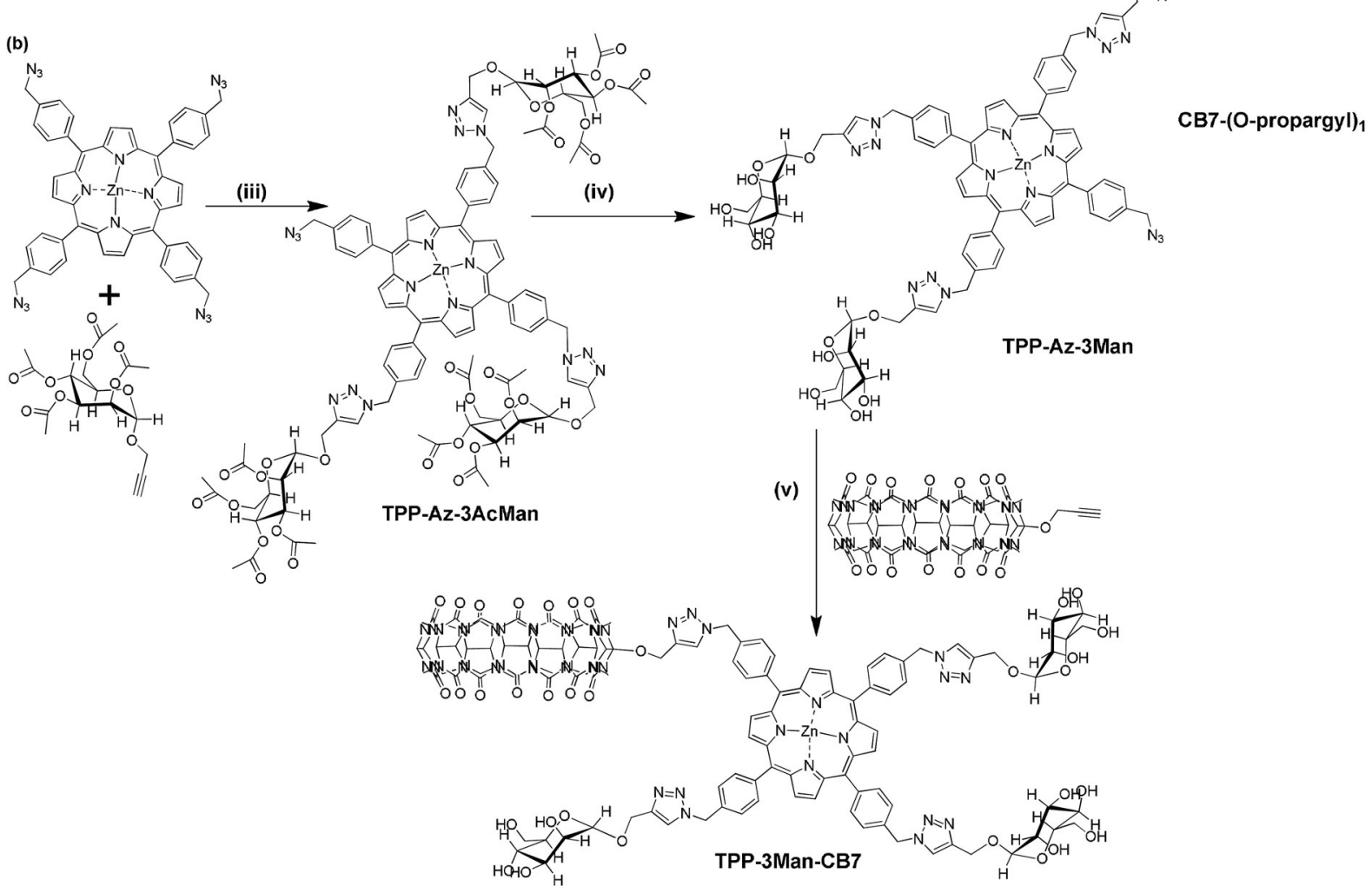

Scheme 1. a) Synthesis of monofunctionalized CB7: i) $\mathrm{K}_{2} \mathrm{~S}_{2} \mathrm{O}_{8}, \mathrm{H}_{2} \mathrm{O}, 85^{\circ} \mathrm{C}$; ii) $\mathrm{NaH}$, propargyl bromide, DMSO, $0-25^{\circ} \mathrm{C}, \mathrm{N}_{2}$ (g), $48 \mathrm{~h}$. b) iii) $\mathrm{Synthesis}$ of the assembly: $\mathrm{CuSO}_{4} \cdot 5 \mathrm{H}_{2} \mathrm{O} / \mathrm{Na}$-L-Ascorbate, THF/ $\mathrm{H}_{2} \mathrm{O}, 60^{\circ} \mathrm{C} ; 14 \mathrm{~h}$. iv) $\mathrm{NaOCH}_{3}, \mathrm{MeOH}, 25^{\circ} \mathrm{C}, 14 \mathrm{~h}$. v) $\mathrm{CuSO}_{4} \cdot 5 \mathrm{H}_{2} \mathrm{O} / \mathrm{Na}$-L-Ascorbate, $\mathrm{DMSO} / \mathrm{H}_{2} \mathrm{O}, 48 \mathrm{~h}$. 

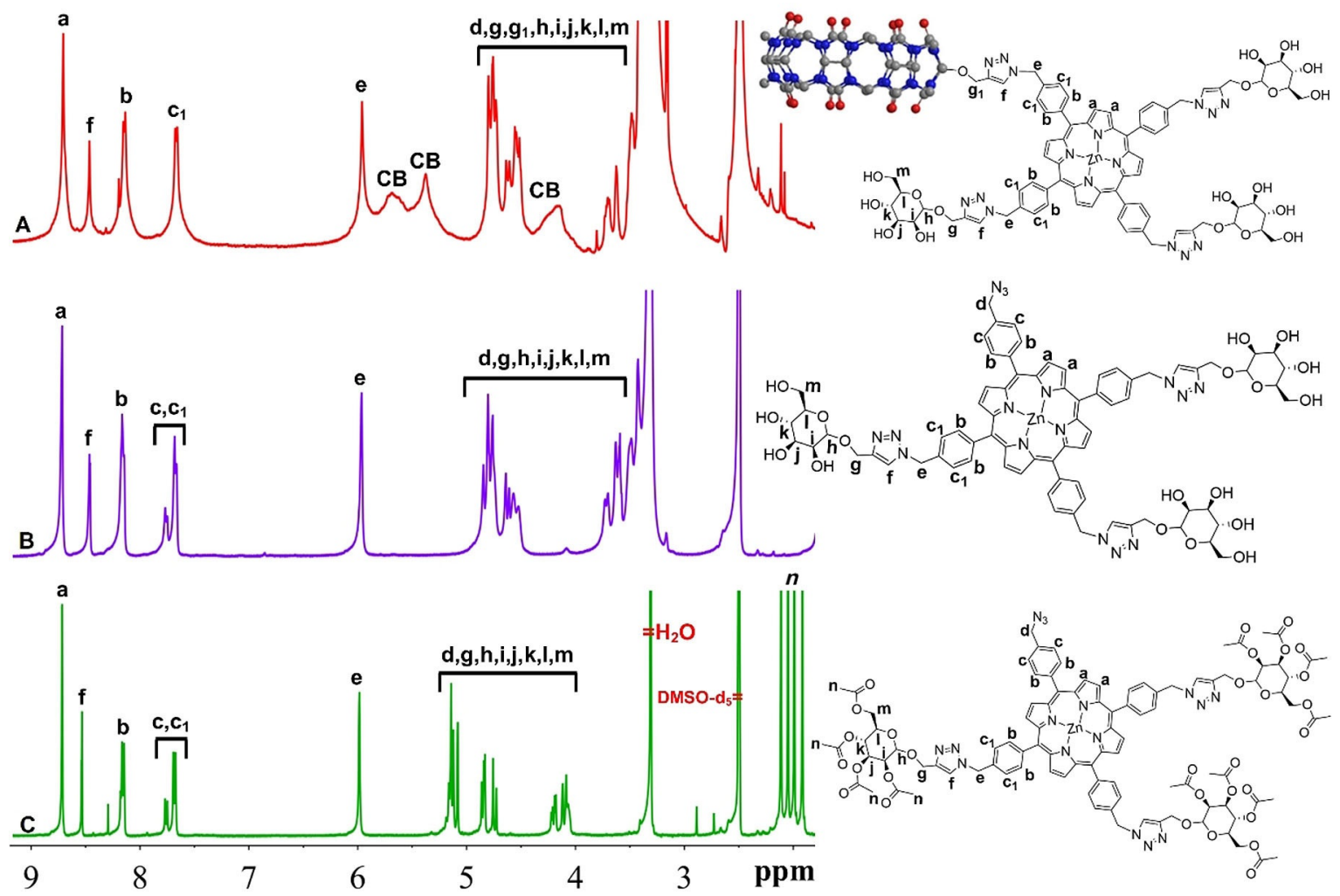

Figure 1. Overlay of the ${ }^{1} \mathrm{H}$ NMR $\left(400 \mathrm{MHz}, 25^{\circ} \mathrm{C}\right.$ ) spectra of A) TPP-3Man-CB7; B) TPP-Az-3Man, and C) TPP-Az-3AcMan (spectra were recorded in [ $\left.\mathrm{D}_{6}\right] \mathrm{DMSO}$ ).

tion started around $517^{\circ} \mathrm{C}$, and probably arose from loss of benzene rings attached to the core.

Acetylated propargylated mannose (1- $\alpha$-propargyloxy mannose) was synthesized by using a reported procedure ${ }^{[14 b]}$ and characterized by ${ }^{1} \mathrm{H}$ NMR and FTIR spectroscopy (Figures S24, S25). The click (CUAAC) reaction between three equivalents of 1 - $\alpha$-propargyloxy mannose and one equivalent $\mathrm{Zn}-\mathrm{TPP}-\mathrm{N}_{3}$ yielded a mixture of analogues of 1-, 2-, 3- and 4-mannosylclicked porphyrins. These were successfully separated by column chromatography to afford TPP-Az-3AcMan (tri-clicked analogue) in $50 \%$ yield, together with $4 \%$ of TPP-3Az-1AcMan (mono-clicked analogue), 16\% of TPP-2Az-2AcMan (di-clicked analogue), and $20 \%$ of TPP-4AcMan (tetra-clicked analogue), successively. TPP-Az-3AcMan was selected for further use because of solubility considerations and it was fully characterized by ${ }^{1} \mathrm{H}$ NMR, ${ }^{13} \mathrm{C}$ NMR, and FTIR spectroscopy and ESI-MS (Figures S26-S29). In the ${ }^{1} \mathrm{H}$ NMR spectrum (Figure 1C), the characteristic singlet at $8.55 \mathrm{ppm}$ for the hydrogen of the triazole ring and the multiplet around $2.00 \mathrm{ppm}$ for acetylic hydrogen atoms are evidence for the attachment of mannosyl units. The peak at $170.1 \mathrm{ppm}$ coming from the carbonyl carbon in ${ }^{13} \mathrm{C}$ NMR further confirmed the presence of acetylated mannose groups attached to TPP (Figure S27). In the ESI-mass spectrum, the related signals are readily assigned to corresponding molecular ions, as shown in Figure S28. Another important proof for the formation of TPP-Az-3AcMan was obtained from the FTIR spectrum, which showed the partial reduction of azide stretching at $2095 \mathrm{~cm}^{-1}$ and the existence of $\mathrm{C}=\mathrm{O}$ stretching peak at $1748 \mathrm{~cm}^{-1}$, as expected (Figure $2 \mathrm{a}$ ).
TPP-Az-3AcMan dissolves well in dimethyl sulfoxide (DMSO), $\mathrm{N}, \mathrm{N}$-dimethylformamide (DMF) and partially in methanol, tetrahydrofuran (THF), chloroform, acetone, and acetonitrile, but not well in either ethanol or water.

Prior to setup the final synthetic step, acetyl groups on mannose of TPP-Az-3AcMan, were hydrolyzed through Zemplén deacetylation using sodium methoxide solution in methanol. ${ }^{[24]}$ The product obtained after hydrolysis (TPP-Az-3Man) dissolved

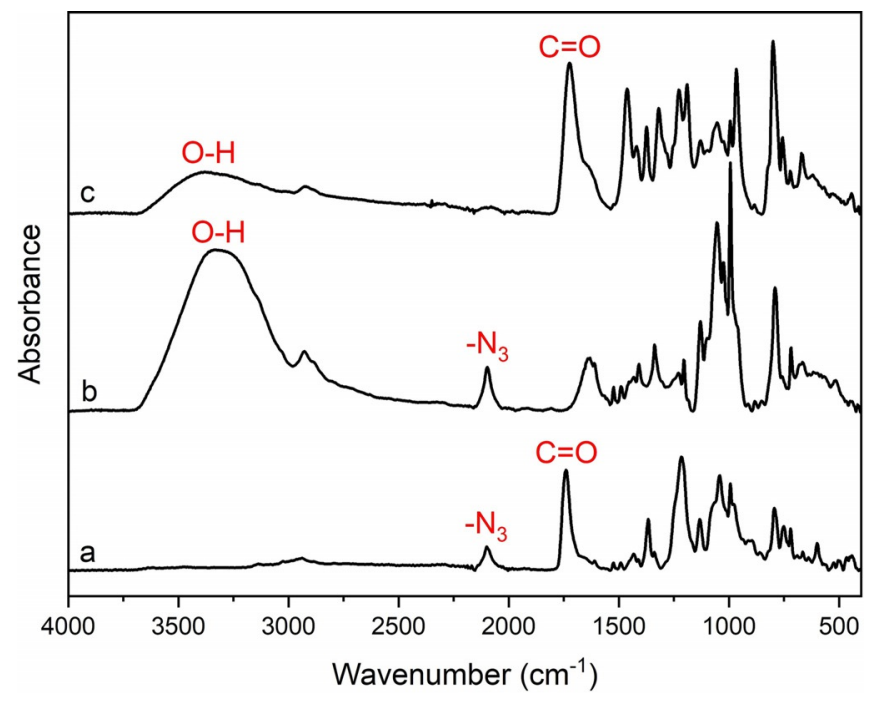

Figure 2. Overlay of the FTIR spectra of a) TPP-Az-3AcMan b) TPP-Az-3Man c) TPP-Az-3Man-CB7 in absorption mode. 
well in DMSO and partially in methanol but it had a poor solubility in water. TPP-Az-3Man was characterized by ${ }^{1} \mathrm{H} N M R$, ${ }^{13} \mathrm{C}$ NMR, FTIR spectroscopy and by ESI-MS (Figures S30-S33). The disappearance of acetylic hydrogen peaks around $2.00 \mathrm{ppm}$ in the ${ }^{1} \mathrm{H}$ NMR spectrum (Figure $1 \mathrm{~B}$ ) and the $\mathrm{C}=\mathrm{O}$ stretching peak at $1748 \mathrm{~cm}^{-1}$ in the FTIR spectrum along with the emergence of a broad peak at $3350 \mathrm{~cm}^{-1}$ for hydroxyl groups, confirmed the success of the deacetylation reaction (Figure $2 \mathrm{~b}$ ). The ESI-mass spectrum clearly shows the molecular ions of the product and there was no trace of the acetylated form (Figure S32).

In the final step, the TPP-CB7 conjugate (TPP-3Man-CB7) was synthesized by a second CuAAC reaction between TPP-Az3 Man and excess CB7-(O-propargyl) in $\mathrm{DMSO} / \mathrm{H}_{2} \mathrm{O}$ mixture (4:1). The product was isolated after purification using sephadex G-25 column ( $\mathrm{MeOH} /$ water, 1:1, v/v) in $91 \%$ yield. The solubility properties of TPP-3Man-CB7 were investigated and summarized as follows: in DMSO, $10 \mathrm{mg} \mathrm{mL}^{-1}$; in $\mathrm{H}_{2} \mathrm{O}, 0.2 \mathrm{mg} \mathrm{mL}^{-1}$ and in $\mathrm{H}_{2} \mathrm{O}$ /DMSO mixture $(4: 1, \mathrm{v} / \mathrm{v}), 2 \mathrm{mg} \mathrm{mL}^{-1}$. It also dissolves in acidic water (e.g., $0.1 \mathrm{M} \mathrm{HCl}$ (aq) solution). It was poorly solubility in neat water, probably due to extensive $\mathrm{H}$ bonding between the mannosyl-OH groups, but the presence of even small amounts of DMSO weakens the interactions and solubilizes the assembly in water. TPP-3Man-CB7 was fully characterized by ${ }^{1} \mathrm{H}$ and ${ }^{13} \mathrm{C}$ NMR, FTIR spectroscopy and ESI-MS (Figures S35-S38). Figure 2 shows the overlaid FTIR spectra of TPP-Az-3AcMan, TPP-Az-3Man and TPP-3Man-CB7 for comparison. The FTIR spectrum of TPP-3Man-CB7 (Figure $2 \mathrm{c}$ ) reveals the absence of azide stretching at $2100 \mathrm{~cm}^{-1}$ and the presence of strong carbonyl stretch at $1725 \mathrm{~cm}^{-1}$, which supports the successful synthesis of TPP-3Man-CB7. Figure $1 \mathrm{~A}$ shows the ${ }^{1} \mathrm{H}$ NMR spectrum of TPP-3Man-CB7 recorded in $\left[\mathrm{D}_{6}\right] \mathrm{DMSO}$. As can be seen from the spectrum, the peaks for porphyrin and mannosyl protons are relatively sharp, but the peaks arising from $C B$ protons are quite broad. In the ${ }^{1} \mathrm{H}$ NMR spectrum, the singlet at $8.49 \mathrm{ppm}$ for the hydrogen of triazole ring formed during the second click reaction and the peak at $155.6 \mathrm{ppm}$ for carbonyl carbon of $\mathrm{CB}$ in ${ }^{13} \mathrm{C}$ NMR further confirms the success of the reaction (Figure S35, S37). In the ESI-MS spectrum, the related signals are readily assigned to corresponding molecular ions as shown in Figure S35.

To find out whether CB7 will be available as a host in the assembly, 1,1'-(1,4-phenylenebis(methylene))-bis(3-methyl- $1 \mathrm{H}$-imidazol-3-ium) iodide (bisimidazolium), which is known to have high affinity toward CB7, was selected as a guest molecule and ${ }^{1} \mathrm{H}$ NMR experiments were carried out. As can be seen from the ${ }^{1} \mathrm{H}$ NMR spectrum of bisimidazolium guest recorded in $\mathrm{D}_{2} \mathrm{O}$ (Figure $3 \mathrm{~A}$ ), chemical shifts for the phenyl and imidazole protons (labeled as $\mathrm{f}$ and $\mathrm{b} / \mathrm{c}$, respectively) overlap and resonate at $7.5 \mathrm{ppm}$. However, upon addition of 1 equiv $\mathrm{CB} 7-\mathrm{OH}_{1}$, the phenyl protons exhibit an upfield shift of around $1 \mathrm{ppm}$ and imidazole protons (labeled as b and c) appear as two distinct peaks (Figure $3 \mathrm{~B}$ ). These changes indicate the encapsulation of phenyl moiety of the imidazole guest by $\mathrm{CB} 7-\mathrm{OH}_{1}$ as the suggested inclusion complex structure shown in Figure 3B. We have also observed similar changes in the ${ }^{1} \mathrm{H}$ NMR spectrum of the TPP-3Man-CB7 (Figure 3C) when bisimidazolium solution

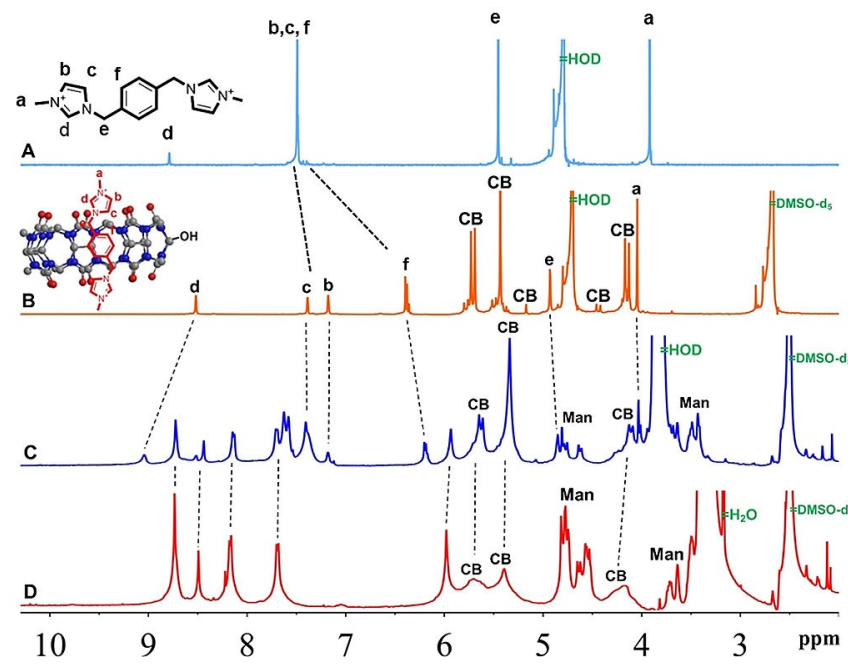

Figure 3. ${ }^{1} \mathrm{H}$ NMR $\left(400 \mathrm{MHz}, 25^{\circ} \mathrm{C}\right)$ spectra of A) 1,1'-(1,4-phenylenebis(methylene))bis(3-methyl- $1 \mathrm{H}$-imidazol-3-ium) iodide (bisimidazolium) (in $\mathrm{D}_{2} \mathrm{O}$ ); B) $\mathrm{CB} 7-\mathrm{OH}_{1}+$ bisimidazolium (1 equiv), recorded in $\left[\mathrm{D}_{6}\right] \mathrm{DMSO} / \mathrm{D}_{2} \mathrm{O}$ mixture $(1: 2, \mathrm{v} / \mathrm{v}) ; \mathrm{C})$ TPP-3Man-CB7 + bisimidazolium (1 equiv) $(1.2 \mathrm{~mm})$ recorded in $\left[\mathrm{D}_{6}\right] \mathrm{DMSO} / \mathrm{D}_{2} \mathrm{O}$ mixture $\left.(2: 1, \mathrm{v} / \mathrm{v}) ; \mathrm{D}\right)$ TPP-3Man-CB7 (1.2 mm, [D $]$ DMSO).

in $\mathrm{D}_{2} \mathrm{O}$ (1 equiv) was added to the NMR tube containing the $\left[\mathrm{D}_{6}\right] \mathrm{DMSO}$ solution of TPP-3Man-CB7. Furthermore, the broadened CB7 peaks acquired their well-defined shapes after complexing with bisimidazolium guest. These observations confirm that CB7 is available as a host for complexation and that there is no conformational restriction for CB7 in the assembly to exhibit its nature as being a receptor.

Photophysical properties of TPP-3Man-CB7, TPP-Az-3AcMan and TPP-Az-3Man in DMSO were also investigated. Figure 4 shows an overlay of the UV/Vis absorbance and fluorescence spectra of TPP-Az-3AcMan, TPP-Az-3Man and TPP-3Man-CB7. UV/Vis absorbance spectra show no significant difference in a typical sharp Soret band $\left(\lambda_{\max }=429 \mathrm{~nm}\right)$ and Q-bands $\left(\lambda_{\mathrm{abs}}=\right.$ 561 and $600 \mathrm{~nm}$ ). Similarly, emission spectra do not show any significant difference $\left(\lambda_{\mathrm{em}}=608\right.$ and $\left.661 \mathrm{~nm}\right)$. The fluorescence quantum yields $\left(\Phi_{\mathrm{f}}\right)$ of TPP-3Man-CB7 and TPP-Az-3Man in DMSO were found to be 3.5 and 4.1 , respectively. The fluores-

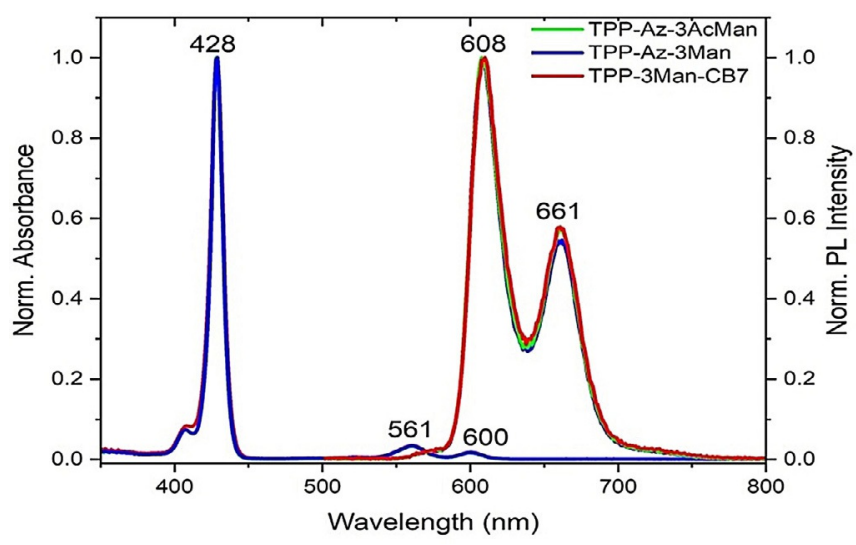

Figure 4. Normalised UV/Vis absorbance and fluorescence spectra of TPP-Az3AcMan (green), TPP-Az-3Man (blue), and TPP-3Man-CB7 (red) in DMSO. 
cence lifetime $(\tau)$ is $1.8 \mathrm{~ns}$ for both TPP-3Man-CB7 and TPP-Az3Man (Figure S34, S40).

Low fluorescence quantum yields of these compounds would suggest that the excited molecules may follow nonradiative relaxation pathways, which could possibly increase their ${ }^{1} \mathrm{O}_{2}$ generation capacity. To prove this, a widely known indirect method for the determination of produced ${ }^{1} \mathrm{O}_{2}$ was employed. 1,3-Diphenylisobenzofuran (DPBF) was used as ${ }^{1} \mathrm{O}_{2}$ trapping agent and time-dependent decrease in the absorbance of DPBF in the presence of photosensitizer upon irradiation was correlated with the amount of ${ }^{1} \mathrm{O}_{2}$ generated. For this experiment, the samples in DMSO were irradiated with $460 \mathrm{~nm}$ LED with 10 second intervals. The reduction in the absorbance intensity of DPBF was monitored with increasing irradiation time (Figure S41). From the absorbance graphs, $-\operatorname{In}[\mathrm{DPBF}] /$ $[D P B F]_{0}$ vs. time plots were extracted to indirectly calculate ${ }^{1} \mathrm{O}_{2}$ quantum yields of the samples using Equation (1):

$\Phi_{\text {sam }}=\Phi_{\mathrm{MB}}\left(m_{\mathrm{sam}} / m_{\mathrm{MB}}\right)\left(F_{\mathrm{MB}} / F_{\mathrm{sam}}\right)$

in which the subscripts ' $\mathrm{MB}^{\prime}$ and 'sam' indicate methylene blue $\left(\Phi_{\mathrm{MB}}=0.52\right.$ in DMSO) and acetylated bis-mannose TPP, hydrolyzed bis-mannose TPP and TPP-3Man-CB[7], respectively; $m$ is the slope of $-\ln [\mathrm{DPBF}] /[\mathrm{DPBF}]_{0}$ vs. time plot and $F$ is the absorption correction factor, which is given by $F=1-10^{-O D}(\mathrm{OD}$ : optical density at the irradiation wavelength). The ${ }^{1} \mathrm{O}_{2}$ quantum yields of the corresponding samples can be ordered as shown in Equation (2) and Figure 5:

TPP-Az-3Man $\approx$ TPP-3Man-CB7 > TPP-Az-3AcMan;

$\left[\Phi_{\Delta}=0.77 \approx 0.77>0.80\right]$

The ${ }^{1} \mathrm{O}_{2}$ quantum yield of unfunctionalized TPP was reported as 0.60 in DMF. ${ }^{[27]}$ The synthesized new materials were seen to have ${ }^{1} \mathrm{O}_{2}$ quantum yields around $80 \%$, which are significantly higher than that of TPP. The reason for the high ${ }^{1} \mathrm{O}_{2}$ quantum yields could be the reduced $\pi-\pi$ interactions between the por-

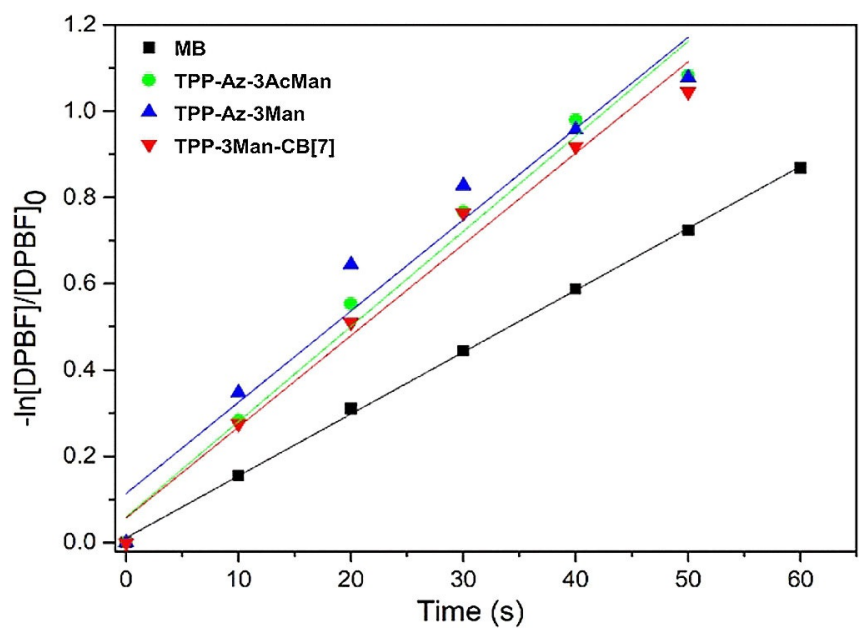

Figure 5. Linearized plots based on the decrease in the absorbance intensity of DPBF in the presence of methylene blue, TPP-Az-3AcMan, TPP-Az-3Man and TPP-3Man-CB7 irradiated at $460 \mathrm{~nm}$ with $10 \mathrm{~s}$ intervals. phyrin cores, resulting from the presence of bulky functional groups (mannosyl and CB7).

\section{Conclusion}

A multifunctional supramolecular assembly based on a photoactive glycosylated porphyrin and covalently attached monofunctionalized CB7 was synthesized for the first time and fully characterized. With a CuAAC reaction of 1- $\alpha$-propargyloxy mannose and $\mathrm{Zn}$-TPP- $\mathrm{N}_{3}$, first trimannosyl clicked porphyrin, TPP-Az-3AcMan, was synthesized and isolated from the other mono-, di- and tetramannosyl analogues and subsequently hydrolyzed to obtain its deacetylated derivative. Trimannosyl clicked porphyrin was selected for use in the construction of the assembly because it allowed us to obtain well-defined and, as result, well-characterized structure after its second CuAAC reaction with mono-propargyloxy-CB7. The resulting assembly dissolves in DMSO $\left(10 \mathrm{mg} \mathrm{mL}^{-1}\right)$, in $\mathrm{H}_{2} \mathrm{O}\left(0.2 \mathrm{mg} \mathrm{mL}^{-1}\right)$, in $\mathrm{H}_{2} \mathrm{O}$ / DMSO mixture $\left(4: 1, \mathrm{v} / \mathrm{v} ; 2 \mathrm{mg} \mathrm{mL}^{-1}\right)$ and in aqueous acid solution.

${ }^{1} \mathrm{O}_{2}$ generation efficiencies of the synthesized compounds were investigated and they were found to be significantly higher than that of the unfunctionalized TPP. Moreover, the availability of the CB7s as a host in the assembly was confirmed by ${ }^{1} \mathrm{H}$ NMR experiments in which the imidazole-based guest was observed to form inclusion complex with the CB7s of the assembly.

This photoactive supramolecular assembly has the potential to be used in multimodal chemo and photodynamic therapies because its photoactive porphyrin core can act as a photosensitizer. To increase the efficiency of the therapy, anticancer drugs or antibiotics, respectively, can be also be encapsulated and carried by CB7 units. This assembly could also be used for photocatalysis and energy harvesting in which CB units could encapsulate, respectively, an analyte and donor/acceptor molecules for efficient photocatalytic and energy transfer processes.

\section{Acknowledgements}

We thank The Scientific and Technological Research Council of Turkey-TÜBITAK for funding (KBAG 215Z035).

\section{Conflict of interest}

The authors declare no conflict of interest.

Keywords: drug delivery • photosensitizers · porphyrinoids singlet oxygen · supramolecular chemistry

[1] a) D. B. Amabilino, D. K. Smith, J. W. Steed, Chem. Soc. Rev. 2017, 46, 2404-2420; b) M. J. Webber, R. Langer, Chem. Soc. Rev. 2017, 46, 66006620.

[2] P. D. Frischmann, K. Mahata, F. Würthner, Chem. Soc. Rev. 2013, 42, $1847-1870$.

[3] I. Beletskaya, V. S. Tyurin, A. Y. Tsivadze, R. Guilard, C. Stern, Chem. Rev. 2009, 109, 1659-1713. 
[4] J. Yang, M.-C. Yoon, H. Yoo, P. Kim, D. Kim, Chem. Soc. Rev. 2012, 41, $4808-4826$

[5] C. M. Drain, A. Varotto, I. Radivojevic, Chem. Rev. 2009, 109, 1630-1658.

[6] M. Ethirajan, Y. Chen, P. Joshi, R. K. Pandey, Chem. Soc. Rev. 2011, 40, $340-362$.

[7] M. A. Rajora, J. W. H. Lou, G. Zheng, Chem. Soc. Rev. 2017, 46, 64336469.

[8] Y.-H. Jeong, H.-J. Yoon, W-D. Jang, Polym. J. 2012, 44, 512-521.

[9] D. Kushwaha, V. K. Tiwari, J. Org. Chem. 2013, 78, 8184-8190.

[10] S. Singh, A. Aggarwal, N. V. S. D. K. Bhupathiraju, G. Arianna, K. Tiwari, C. M. Drain, Chem. Rev. 2015, 115, $10261-10306$.

[11] F. Giuntini, F. Bryden, R. Daly, E. M. Scanlanb, R. W. Boyle, Org. Biomol. Chem. 2014, 12, $1203-1206$

[12] M. H. Staegemann, B. Gitter, J. Dernedde, C. Kuehne, R. Haag, A. Wiehe, Chem. Eur. J. 2017, 23, 3918-3930.

[13] M. H. Staegemann, S. Gräfe, R. Haag, A. Wiehe, Org. Biomol. Chem 2016, 14, 9114-9132.

[14] a) G. Garcia, D. Naud-Martin, D. Carrez, A. Croisy, P. Maillard, Tetrahedron 2011, 67, 4924-4932; b) O. B. Locos, C. C. Heindl, A. Corral, M. O. Senge E. M. Scanlan, Eur. J. Org. Chem. 2010, 1026-1028.

[15] a) A. C. Bhasikuttan, H. Pal, J. Mohanty, Chem. Commun. 2011, 47, 9959 9971; b) B. Girek, W. Sliwa, J. Inclusion Phenom. Macrocyclic Chem. 2015 $81,35-48$; c) D. Tuncel, N. Cındır, U. Koldemir, J. Inclusion Phenom. Mac rocyclic Chem. 2006, 55, 373-380; d) S. Liu, A. D. Shukla, S. Gadde, B. D. Wagner, A. E. Kaifer, L. Isaacs, Angew. Chem. Int. Ed. 2008, 47, $2657-$ 2660; Angew. Chem. 2008, 120, 2697-2700; e) J. Mohanty, A. C. Bhasikuttan, S. D. Choudhury, H. Pal, J. Phys. Chem. B 2008, 112, 10782 10785 ; f) N. Barooah, A. C. Bhasikuttan, V. Sudarsan, S. D. Choudhury, H. Pal, J. Mohanty, Chem. Commun. 2011, 47, 9182-9184; g) A. Koc, D. Tuncel, Isr. J. Chem. 2017, 57, 1-10, https://doi.org/10.1002/ ijch.201700114.

[16] a) W. Lei, G. Jiang, Q. Zhou, Y. Hou, B. Zhang, X. Cheng, X. Wang, Chem PhysChem 2013, 14, 1003-1008; b) K. Liu, Y. Liu, Y. Yao, H. Yuan, S Wang, Z. Wang, X. Zhang, Angew. Chem. Int. Ed. 2013, 52, 8285-8289, Angew. Chem. 2013, 125, 8443-8447; c) L. Chen, H. Bai, J.-F. Xu, S Wang, X. Zhang, ACS Appl. Mater. Interfaces 2017, 9, 13950-13957; d) W. Lei, G. Jiang, Q. Zhou, B. Zhang, X. Wang, Phys. Chem. Chem. Phys.
2010,12, 13255-13260；e) J. Cáceres, J. Robinson-Duggon, A. Tapia, C. Paiva, M. Gomez, C. Bohne, D. Fuenteal, Phys. Chem. Chem. Phys. 2017, 19, 2574.

[17] a) E. Masson, X. Ling, R. Joseph, L. Kyeremeh-Mensah, X. Lu, RSC Adv. 2012, 2, 1213-1247; b) S. Gürbüz, M. Idris, D. Tuncel, Org. Biomol. Chem. 2015, 13, 330-347; c) K. I. Assaf, W. M. Nau, Chem. Soc. Rev. 2015 44, 394-418; d) D. Shetty, J. K. Khedkar, K. M. Park, K. Kim, Chem. Soc Rev. 2015, 44, 8747-8761; e) S. J. Barrow, S. Kasera, M. J. Rowland, J. Del Barrio, O. A. Scherman, Chem. Rev. 2015, 115, 12320-12406.

[18] R. H. Gao, L. X. Chen, K. Chen, Z. Tao, X. Xiao, Coord. Chem. Rev. 2017 $348,1-24$.

[19] a) N. Zhao, G. O. Lloyd, O. A. Scherman, Chem. Commun. 2012, 48, 3070-3072; b) J. A. McCune, E. Rosta, O. A. Scherman, Org. Biomol. Chem. 2017, 15, 998.

[20] Y. Ahn, Y. Jang, N. Selvapalam, G. Yun, K. Kim, Angew. Chem. Int. Ed. 2013, 52, 3140-3144; Angew. Chem. 2013, 125, 3222-3226.

[21] N. Dong, J. He, T. Li, A. Peralta, M. R. Avei, Mi. Ma, A. E. Kaifer, J. Org. Chem. 2018, 83, 5467-5473.

[22] M. M. Ayhan, H. Karoui, M. Hardy, A. Rockenbauer, L. Charles, R. Rosas, K. Udachin, P. Tordo, D. Bardelang, O. Ouari, J. Am. Chem. Soc. 2015 137, 10238-10245.

[23] Y. Yu, J. Li, M. Zhang, L. Cao, L. Isaacs, Chem. Commun. 2015, 51, 3762 3765.

[24] A. T. Bockus, L. C. Smith, A. G. Grice, O. A. Ali, C. C. Young, W. Mobley, A. Leek, J. L. Roberts, B. Vinciguerra, L. Isaacs, A. R. Urbach, J. Am. Chem. Soc. 2016, 138, 16549-16552.

[25] a) A. Day, A. P. Arnold, R. J. Blanch, B. Snushall, J. Org. Chem. 2001, 66, 8094-8100; b) S. Y. Jon, N. Selvapalam, D. H. Oh, J.-K. Kang, S.-Y. Kim, Y. J. Jeon, J. W. Lee, K. Kim, J. Am. Chem. Soc. 2003, 125, 10186.

[26] L. Wen, M. Li, J. B. Schlenoff, J. Am. Chem. Soc. 1997, 119, 7726-7733.

[27] R. Khan, M. Idris, D. Tuncel, Org. Biomol. Chem. 2015, 13, 10496-10504.

Manuscript received: August 6, 2018

Revised manuscript received: August 28, 2018

Accepted manuscript online: August 30, 2018

Version of record online: October 5, 2018 